INTERNATIONAL JOURNAL OF MULTidisciplinARY RESEARCH AND ANALYSis

ISSN(print): 2643-9840, ISSN(online): 2643-9875

Volume 04 Issue 11 November 2021

DOI: 10.47191/ijmra/v4-i11-34, Impact Factor: 6.072

Page No.- $1695-1700$

\title{
Features of The Processes of Clinker Formation When Using Solid Waste From Caprolactic Production As A Mineralizer
}

\author{
Nimchik Alexey Grigoryevich ${ }^{1}$, Zulayho Raimovna Kadyrova ${ }^{2}$ Khikmatulla Lutpullayevich Usmanov ${ }^{3}$ \\ ${ }^{1}$ Candidate of chemical sciences, Institute of General and inorganic chemistry, Academy of Sciences of the Republic of \\ Uzbekistan \\ ${ }^{2}$ Doctor of chemical sciences, professor, Institute of general and inorganic Chemistry of Academy of Sciences of the Republic of \\ Uzbekistan \\ ${ }^{3}$ Candidate of technical sciences, Institute of general and inorganic chemistry of Academy of Sciences of the Republic of \\ Uzbekistan
}

ABSTRACT: The possibility of using a soda-sulfate mixture - an alkaline waste from the production of caprolactam, as a mineralizing additive in a Portland cement raw mixture containing, as a silica-containing component, flotation tailings of the lead-concentrating plant of Almalyk MMC, has been studied. The effect of this additive on the processes of mineral formation during the synthesis of Portland cement clinker is shown. The possibility of additional recovery of residual non-ferrous metals lead and copper - by sublimation and trapping of their chlorides has been established.

KEYWORDS: soda-sulfate mixture, flotation waste, clinker formation, nonferrous metals, additional recovery, firing temperature.

\section{INTRODUCTION}

The use of by-products and various industrial wastes in the production of building materials, in particular, cement, are devoted to the work of many researchers [1-12]. In the cement industry, waste and by-products of various industries are mainly used as a component of a raw mixture, a mineralizer during firing, or an active mineral additive when grinding clinker.

Among the industries that generate the largest amount of large-tonnage waste are chemical, non-ferrous and ferrous metallurgy, mining, coal, heat and power, etc.

Industrial waste from many industries contains components such as $\mathrm{SiO}_{2}, \mathrm{Al}_{2} \mathrm{O}_{3}, \mathrm{Fe}_{2} \mathrm{O}_{3}, \mathrm{CaCO}_{3}$, $\mathrm{MgO}$, etc., which are essential components in the production of building materials. One of the largest consumers of natural raw materials is the cement industry. The use of waste and by-products from various industries contributes not only to saving fuel, electricity, and natural raw materials, but also significantly increases production. The area allotted for quarries and dumps suitable for agriculture is also reduced, which leads to an improvement in the ecological state of the environment.

One of the largest enterprises in Central Asia is the Almalyk Mining and Metallurgical Combine, which annually processes millions of tons of ore at the concentration plants. In the process of obtaining marketable products, various wastes are formed, containing a significant amount of residual non-ferrous metals, lead, zinc, copper and rare earth metals platinum, gold, silver, rhenium, selenium and others. The content of non-ferrous, rare and noble metals ranges from: copper from 0.1 to $0.2 \%$, lead from 0.1 to $0.3 \%$, rhenium from 0.03 to $0.08 \%$, gold 0.3 grams per ton, silver 1.6 grams per ton of flotation waste [13].

The scientific information available in the literature on the effect of alkali metal chlorides and various alkali-containing industrial wastes on the chemical reactions occurring in the cement raw mixture during roasting, as well as the sublimation of the residual metals contained in it, are very contradictory.

In this regard, it was of interest to study the possibility of using the tailings of the lead dressing plant of the Almalyk Mining and Metallurgical Combine (AGMK) in the production of Portland cement clinker as a raw material and additional recovery of residual non-ferrous metals, as well as to determine the construction and technical properties of the resulting Portland cement. 
Features of The Processes of Clinker Formation When Using Solid Waste From Caprolactic Production As A Mineralizer

\section{RESEARCH METHODS}

To study the physicochemical properties of raw mixtures and cement clinker synthesized on their basis, standard chemical, X-ray phase, differential thermal, petrographic, atomic absorption and ethyl glycerate analysis methods were used. Based on the results of these analyzes, the mechanism and kinetics of clinker formation during the firing of cement raw mixtures were studied. The kinetics of sublimation of non-ferrous metals contained in residual amounts in the flotation waste of a lead concentrator was determined by the value of the residual amount of metals in clinker by the atomic absorption method.

\section{SOURCE MATERIALS}

Limestone is the main component of the raw mixture in the synthesis of Portland cement clinker, which contains at least $50 \%$ calcium carbonate- $\mathrm{CaCO}_{3}$ with an admixture of clay materials, dolomite, silica, iron oxide and aluminum. Limestone of the Shavazsai deposit is characterized by a varied crystalline structure, uniformly granular, but with grains of various shapes, with a volumetric weight of $2.5 \mathrm{t} / \mathrm{m} 3$ and a compressive strength of $140 \mathrm{~kg} / \mathrm{cm}^{2}$ (Table 1). The results of X-ray phase analysis of limestone showed the presence of $d=0.303,1.91,1.87 \mathrm{~nm}$. Corresponding to calcium carbonate and an insignificant amount of impurities in the form of $\mathrm{SiO}_{2}$ with $\mathrm{d}=0.334,0.246,0.181,0.153 \mathrm{~nm}$.

Table 1.The chemical composition of the research objects used.

\begin{tabular}{|l|l|l|l|l|l|l|l|l|l|l|}
\hline Name & $\mathrm{SiO}_{2}$ & $\mathrm{Al}_{2} \mathrm{O}_{3}$ & $\mathrm{Fe}_{2} \mathrm{O}_{3}$ & $\mathrm{CaO}$ & $\mathrm{MgO}$ & $\mathrm{Na}_{2} \mathrm{O}$ & $\mathrm{K}_{2} \mathrm{O}$ & $\mathrm{SO}_{3}$ & $\mathrm{PPP}$ & Sume \\
\hline $\begin{array}{l}\text { Limestone } \\
\text { Shavazsay }\end{array}$ & 4,03 & 1,00 & 0,20 & 52,32 & 1,06 & 0,1 & 0,1 & - & 41,08 & 100,31 \\
\hline SOF tails & 45,75 & 8,72 & 7,19 & 14,59 & 7,10 & 2,00 & 0,98 & 2,98 & 8,83 & 99,16 \\
\hline Slag AGMK & 35,46 & 6,34 & 52,14 & 1,45 & 0,46 & - & - & 4,0 & - & 99,86 \\
\hline
\end{tabular}

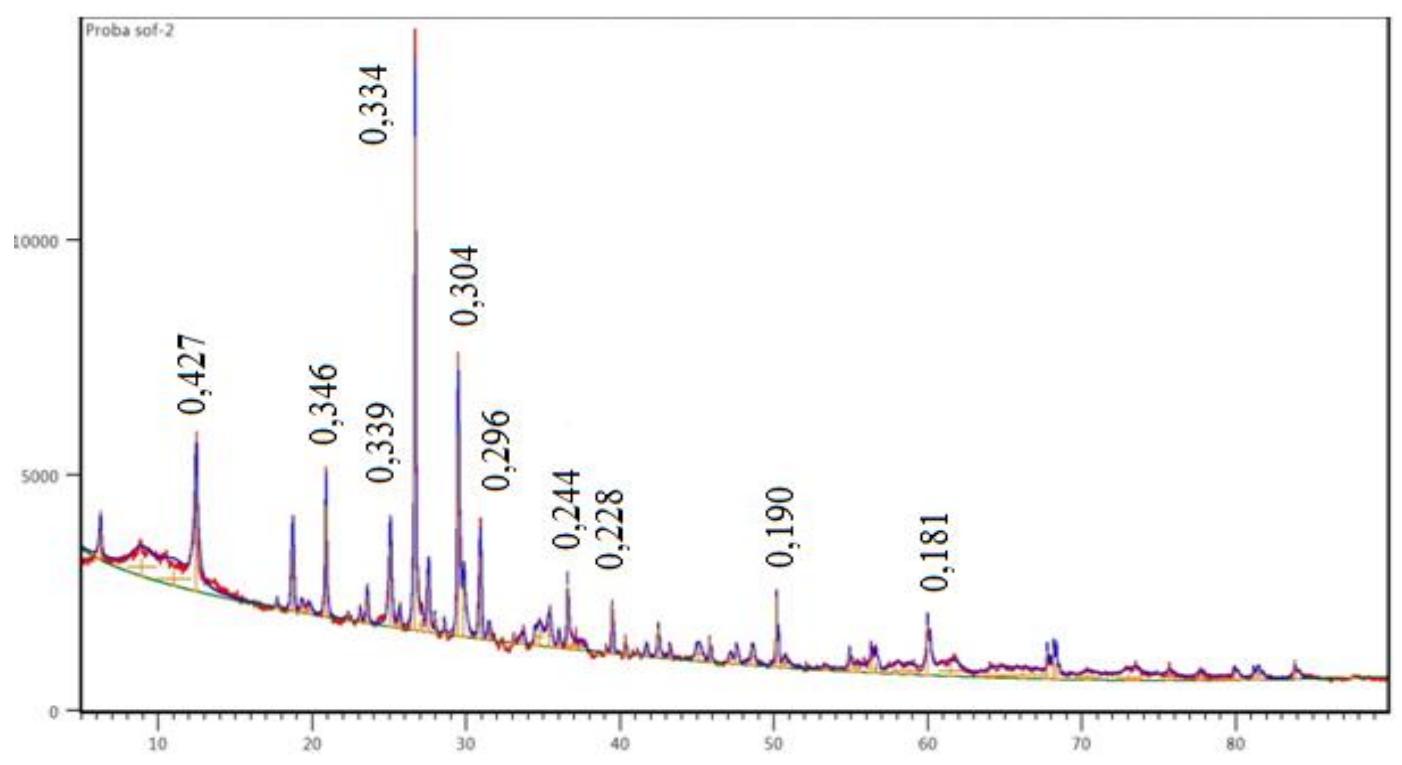

Figure 1. X-ray diffraction pattern of the flotation waste of a lead concentrator.

The main constituents of the tails are; oxides of silicon, calcium, aluminum and magnesium with the following mineralogical composition: quartz, calcite, dolomite, feldspar (Fig. 1). In addition, these wastes contain in their composition a residual amount of a number of rare earth and non-ferrous metals, as noted earlier, in particular copper 0.04-0.05\% and lead 0.1-0.3\%. 
Features of The Processes of Clinker Formation When Using Solid Waste From Caprolactic Production As A Mineralizer

Table 2. The substance composition of the solid alkaline waste from the production of caprolactam.

\begin{tabular}{|l|}
\hline Solid alkaline waste (soda-sulfate mixture) TU 113-03-23-19-83 \\
\hline Mass fraction of $\mathrm{NaCO}_{3}$, not less than $55 \%$ \\
\hline Mass fraction of $\mathrm{NaOH}$, not less than $15 \%$ \\
\hline Mass fraction of $\mathrm{Na}_{2} \mathrm{SO}_{4}$, no more than $30 \%$ \\
\hline Mass fraction of $\mathrm{NaCl}$, no more than $15 \%$ \\
\hline
\end{tabular}

For the purpose of additional extraction of these metals in the process of firing the cement raw mixture as a chlorinator of metals, a solid alkaline waste was used - a dark gray color, resulting from the thermal decomposition of wastewater and distillation residues - a soda-sulfate mixture TU 113-03-23-19-83 [14 ] accumulated in the dump formed during the functioning of caprolactam production at the Chirchik chemical plant with the following mineralogical composition (Table 2).

As an iron-containing component in the raw mixture was usedprocessed slag from the copper-smelting production of AMMC (Table 1).

\section{RESEARCH RESULTS AND DISCUSSION}

For research according to the generally accepted method [15], cement raw mixtures with different saturation coefficient $\mathrm{KH}=$ $0.86-0.89$ and silica modulus $n=2.36-2.41$ were calculated, and alkaline waste was added in an amount of $0.5-5,0 \%$ of the total mass of raw mixtures.

Raw materials in the corresponding calculated ratio were ground in a ball mill to a fineness of $8.0-10.0 \%$ of the residue on a sieve No. 008 . The prepared raw charge was moistened by adding water to $8 \%$ by weight of the mixture and molded in metal molds into tablets with a diameter of $20 \mathrm{~mm}$ and $\mathrm{h}=5 \mathrm{~mm}$ under a hydraulic press at a pressure of $20 \mathrm{MPa}$. The samples obtained were fired in a laboratory furnace with silicon carbide heaters at a temperature of $1400^{\circ} \mathrm{C}$ with holding at a maximum temperature of $30 \mathrm{~min}$. The rise in temperature $250^{\circ} \mathrm{C}$ per hour. The resulting sintered material, cement clinker, was quenched in air. The results of chemical-analytical and physicochemical analysis of clinkers with the addition of alkaline waste showed that they are identical in most of their characteristics with non-additive clinker based on the studied cement raw mixtures.

To determine the degree of sublimation of non-ferrous metals, the atomic adsorption method of elementary analysis was used, and the components included in the composition of the waste - calcium and sodium chlorides, calcium sulfate were used as chlorinating agents in the chloride sublimation. A characteristic feature of the chlorination process is a high rate of chemical reactions and a high degree of chlorination of all components. At the same time, chloride sublimation provides for the transfer of metals into volatile chlorides and their subsequent capture from gases and dust into concentrated products. The results of the analysis showed that the degree of sublimation of non-ferrous metals $\mathrm{Pb}$ and $\mathrm{Cu}$ is in direct proportion to the amount of added alkaline waste (Table 3 ). The table shows that the optimal amount for maximum extraction of non-ferrous metals is $0.8-1.0 \%$ of the mass of the raw mixture.

Table 3. Dependence of the remaining unrecovered metals on the amount of additives in the cement raw mixture with SOF waste, at a temperature of $1420^{\circ} \mathrm{C}$ and a firing time of 20 minutes.

\begin{tabular}{|l|l|l|l|l|l|}
\hline \multirow{2}{*}{$\begin{array}{l}\text { No. } \\
\text { Experience }\end{array}$} & \multirow{2}{*}{$\begin{array}{l}\text { Amount of } \\
\text { alkaline } \\
\text { additives, } \%\end{array}$} & \multicolumn{2}{|l|}{ Metal content in cement clinker, g / t } & \multicolumn{2}{l|}{$\begin{array}{l}\text { Residual metal content in } \\
\text { synthesized clinker, in\% }\end{array}$} \\
\cline { 3 - 6 } & & $\mathrm{Pb}$ & $\mathrm{Cu}$ & $\mathrm{Pb}$ & $\mathrm{Cu}$ \\
\hline 1 & 0,0 & 1124 & 264 & 100 & 100 \\
\hline 2 & 0,2 & 1012 & 237 & 90 & 90 \\
\hline 3 & 0,4 & 685,7 & 140 & 39 & 47 \\
\hline 4 & 0,6 & 247,8 & 87,2 & 22 & 33 \\
\hline 5 & 0,8 & 67,7 & 73,9 & 6 & 28 \\
\hline 6 & 1,0 & 33,7 & 29,1 & 3 & 11 \\
\hline
\end{tabular}

The conducted studies of the dependence of the sublimation of accompanying metals contained in the charge at different firing temperatures and amounts of alkaline additives on the course of caprolactam production have shown that the degree and rate of metal extraction to a large extent depends on the temperature and amount of the additive, in addition, the firing time is also 
Features of The Processes of Clinker Formation When Using Solid Waste From Caprolactic Production As A Mineralizer

of great importance.

It was found that the use of solid alkaline waste containing in its composition a number of chlorides more actively chlorinates the metals in the cement raw mixtures than individual chlorides, as a result of which 89-96\% of copper and lead metals are sublimed (Table 4).

Table 4. Dependence of the sublimation of metals on the temperature and time of firing a cement raw mixture with a SOF waste.

\begin{tabular}{|c|c|c|c|c|c|}
\hline \multirow[t]{2}{*}{ Mix No } & \multirow[t]{2}{*}{ Additive amount, $\%$} & \multirow{2}{*}{$\begin{array}{l}\text { T roasting, } \\
\mathrm{OC}\end{array}$} & \multirow{2}{*}{$\begin{array}{l}\text { Firing time, } \\
\text { in min }\end{array}$} & \multicolumn{2}{|c|}{ Metals recovery rate, $\%$. } \\
\hline & & & & $\mathrm{Pb}$ & $\mathrm{Cu}$ \\
\hline 1 & \multirow{3}{*}{0,6} & 1000 & 40 & 43 & 32 \\
\hline 2 & & 1200 & 30 & 62 & 49 \\
\hline 3 & & 1400 & 20 & 78 & 66 \\
\hline 4 & \multirow{3}{*}{1,0} & 1000 & 40 & 64 & 46 \\
\hline 5 & & 1200 & 30 & 78 & 58 \\
\hline 6 & & 1400 & 20 & 96 & 89 \\
\hline
\end{tabular}

The processes of formation of clinker minerals were controlled by determining the kinetics of assimilation of free lime in the studied clinkers by the alcohol-glycerate method [16]. The results of the analyzes showed that the temperature of the complete assimilation of $\mathrm{CaO}$ free in the raw mixtures is in the range of $1370-1400^{\circ} \mathrm{C}$ with a 30 -minute holding at a given temperature. Based on the results obtained, it can be assumed that the alkaline waste used intensifies the processes occurring during the firing of the studied raw mixtures and contributes to a decrease in the temperature of completion of mineral formation reactions during the synthesis of Portland cement clinker by $50-70{ }^{\circ} \mathrm{C}$ (Table 5).

Table 5.Changes in the amount of CaOf in clinkers, depending on the addition of alkaline waste at a firing temperature of $1400^{\circ} \mathrm{C}$.

\begin{tabular}{|l|l|l|}
\hline Cement clinker & Alkaline waste addition,\% & CaO free content in clinker \\
\hline Clinker without additive & - & 0,24 \\
\hline Clinker 1 & 0,6 & 0,12 \\
\hline Clinker 2 & 0,8 & 0,06 \\
\hline Clinker 3 & 1,0 & 0,02 \\
\hline Clinker 4 & 1,5 & 0,32 \\
\hline
\end{tabular}

An analysis of the synthesized clinkers using a complex of physicochemical methods showed that the most optimal composition for obtaining Portland cement clinker is with $\mathrm{KN}=0.89$ and $\mathrm{n}=2.38$.

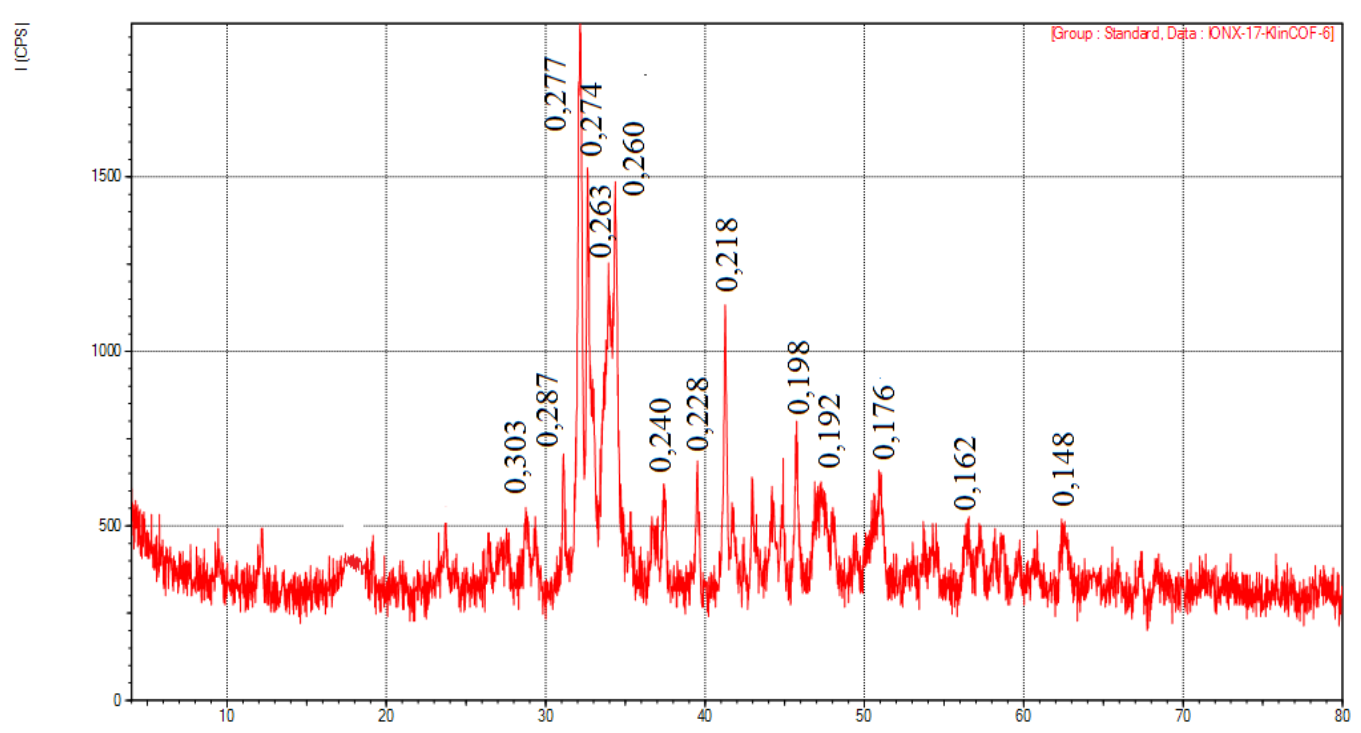

Figure: 2 X-ray diffraction pattern of synthesized clinker with $\mathrm{KN}=0.89$ and $n-2.36$. 
Features of The Processes of Clinker Formation When Using Solid Waste From Caprolactic Production As A Mineralizer

X-ray phase analysis of the studied clinkers revealed that well-crystallized minerals were formed in all samples: alite with $d=$ $0.303,0.277,0.274,0.259 \mathrm{~nm}$; belite with $d=0.287,0.279,0.260 \mathrm{~nm}$, as well as tricalcium aluminate with $d=0.270,0.191$, $0.155 \mathrm{~nm}$ (Fig. 2).

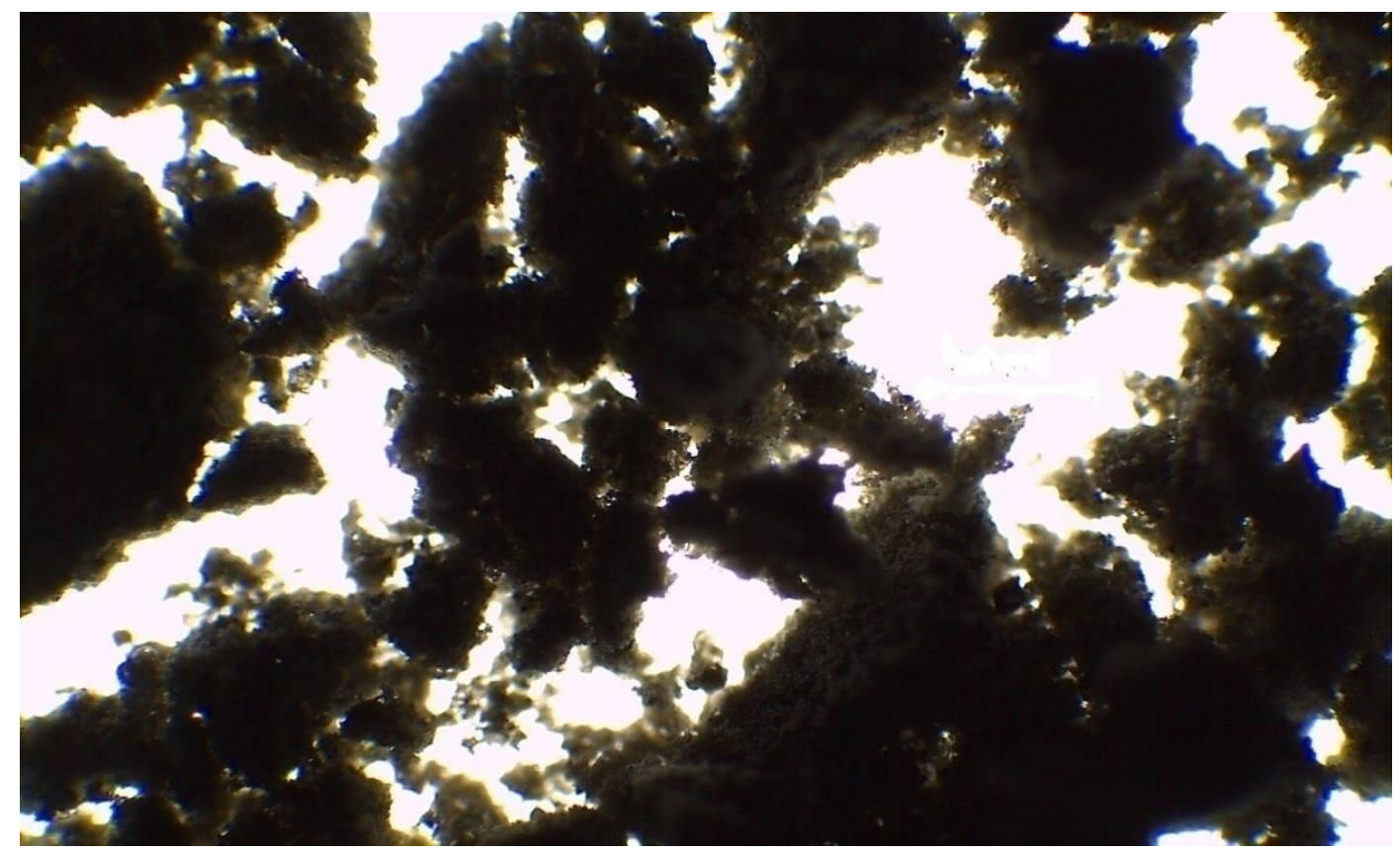

Figure: 3. Petrographic image of synthesized clinker

These results correlate well with the data of petrographic analysis, where well-formed crystals of alite and belite are observed in clinkers with an optimal addition of alkaline waste in an amount of 0.8-1.0\%. Alite in these clinkers has a well-defined hexagonal shape with a size of 50-60 microns, and whitens brown ovals of 20-30 microns.

\section{CONCLUSION}

The studies have shown that the use of alkaline waste from caprolactam production in the optimal amount within $0.8-1.0 \%$ in Portland cement raw mixtures based on the flotation waste of a lead dressing plant reduces the clinker formation temperature by $50-70{ }^{\circ} \mathrm{C}$ and increases the amount of lead and zinc up to $89-97 \%$.

Thus, it can be assumed that the alkaline waste used has a high mineralizing effect of clinker formation and an active chlorinating effect on the sublimation of residual non-ferrous metals.

\section{REFERENCES}

1) Babayan. D. G, Chilingaryan N.V., Tadevosyan C. C. Influence of alkaline and sulfate impurities on the roasting process. Infor. technologies and management, 2006, No. 3, part 1, P. 246-254.

2) Gurevich B. I, Tyukavkina V. V Binding materials from non-ferrous metallurgy slags (Institute of Chemistry and Technology of Rare Elements and Mineral Raw Materials named after IV Tananaev KSC RAS) Tsv. Metallurgy, 2007, No.4, P.10-16.

3) Shamadinova N. E., Adinaev Kh. A., Atakuziev T. A. Low-temperature firing cements based on industrial waste // Universum: Engineering science; electron. Scientific. zhurn. 2018. No.1 (46).

4) Nudelman B.I., Galimova G.A., Gasanova A.A., Chepkolenko M.G. "Raw mix for the production of cement clinker." A.S. No. 936590 C 04 B7 / 38.

5) Borisov I.N. Complex use of technogenic materials in cement clinker firing // Inform Cement. - Moscow, 2009. No -2. - P. 41-47.

6) Zhao Qinglin, Freyburg Ernst, Stark Jochen, Zhou Mingkai. Characteization of the microsctructure and mineral phases of German iron and steel slags // Zement-Kalk-Gips Int.- Bauverlag (Germany), 2009.-V.62.-No.4.- P. 87-94.

7) Zhou Cui. Acquisition of energy- efficient, high - strength, cement withuse of steel industry slags // Cement Engineering / Shui Ni Gong Cheng.-2005.-No.5.-P. 1-5. 
Features of The Processes of Clinker Formation When Using Solid Waste From Caprolactic Production As A Mineralizer

8) Klassen V.K, Shilova I.A., Tekucheva E.V. Features of the processes of clinker formation and hydration of cement when using steel-making slags and partially decarbonized chalk as raw materials // Technics and technology of silicates. Moscow, 2007. - No. 2 - P. 118-124.

9) Ronov A.V., Babaeva A.V., Shibakova V.S., Tikhomirova I.N. Cement based on silicate waste from the metallurgical industry // Advances in chemistry and chemical technology. Volume 24.2010. -№6.- P. 111-114.

10) Larionov L.M., Kondratyev V.V. Kuzmin M.P. Ways of using carbon-containing waste from aluminum production // Bulletin of the Irkutsk State Technical University. 2017.V.21. No. 4. Pp. 139-146.

11) Sitko MK, Starodubenko NG Research of the influence of mineralizers on the process of firing Portland cement clinker // Proceedings of BSTU. Chemistry and technology of inorganic substances. 2016. No. 3. P. 106-110.

12) Aliev S. A., Murtazaeva R. S, Salamanova M. Sh. Structure and properties of alkaline activation binders using cement dust // 2019No. 46 (2): P. 148-157.

13) Valiev. Kh. R, Khudoyarov. S. R. Research of the possibility of complex processing of industrial waste from AMMC. Materials of the republican scientific and technical seminar. (Problems of processing mineral raw materials in Uzbekistan) 3-4 October. 2005, P. 34-36.

14) Soda-sulphate mixture (technological industrial waste of caprolactam production) TU 113-03-23-19-83.

15) Kuzmenkov M.I., Kunitskaya T.S. Astringents and technology for the production of products based on them // Minsk, BSTU, - 2003.- P. 216.

16) Gorshkov V.S., Timashev V.V., Savelyev V.G. Methods of physical and chemical analysis of binders // M., Higher school.1981.-P.333. 